Article

\title{
Picture Power? The Contribution of Visuals and Text to Partisan Selective Exposure
}

\author{
Thomas E. Powell ${ }^{1, *}$, Toni G. L. A. van der Meer ${ }^{1}$ and Carlos Brenes Peralta ${ }^{2}$ \\ ${ }^{1}$ Amsterdam School of Communication Science, University of Amsterdam, Amsterdam, 1012 WX, The Netherlands; \\ E-Mails: t.e.powell@hotmail.com (T.E.P.), g.l.a.vandermeer@uva.nl (T.G.L.A.v.d.M.) \\ ${ }^{2}$ Centre for Political Science, University of Costa Rica, San Jose, 11501-2060, Costa Rica; \\ E-Mail: brenesc@gmail.com (C.B.P.) \\ * Corresponding author
}

Submitted: 21 January 2019 | Accepted: 7 June 2019 | Published: 30 July 2019

\begin{abstract}
Today's high-choice media environment allows citizens to select news in line with their political preferences and avoid content counter to their priors. So far, however, selective exposure research has exclusively studied news selection based on textual cues, ignoring the recent proliferation of visual media. This study aimed to identify the contribution of visuals alongside text in selective exposure to pro-attitudinal, counter-attitudinal and balanced content. Using two experiments, we created a social media-style newsfeed with news items comprising matching and non-matching images and headlines about the contested issues of immigration and gun control in the U.S. By comparing selection behavior of participants with opposing prior attitudes on these topics, we pulled apart the contribution of images and headlines to selective exposure. Findings show that headlines play a far greater role in guiding selection, with the influence of images being minimal. The additional influence of partisan source cues is also considered.
\end{abstract}

\section{Keywords}

balanced content; experimental research; image; selective exposure; text; visual communication

\section{Issue}

This article is part of the issue "Selective Exposure in a Changing Political and Media Environment", edited by María Luisa Humanes (University Rey Juan Carlos, Spain).

(C) 2019 by the authors; licensee Cogitatio (Lisbon, Portugal). This article is licensed under a Creative Commons Attribution 4.0 International License (CC BY).

\section{Introduction}

The last two decades have seen an explosion both in the diversity of choice available to news audiences and in the visualization of news media. Today's fragmented and high-choice media environment enables citizens to select news that matches their political preferences, whilst avoiding information counter to their priors (Sunstein, 2009). In turn, concerns exist that selective exposure contributes to an increasingly polarized citizenry (Stroud, 2010; but see Nelson \& Webster, 2017; Van Aelst et al., 2017). So far, however, scholars of selective exposure have exclusively studied news selection based on textual cues, ignoring concurrent technological advancements that yielded a proliferation of visual media (Fahmy, Bock,
\& Wanta, 2014). Images now take centre stage in news and provide eye-catching cues for selection (Zillmann, Knobloch, \& Yu, 2001). However, as yet, it is not understood what role visuals play in partisan selective exposure, or whether they might even help to counter it.

The relevance of visuals in selective exposure is illustrated by contested political issues which are also often highly visual. When reporting such issues news organisations can adopt opposing positions which are presented both textually as well as visually. For instance, headlines and images can help frame refugees as innocent 'victims' or dangerous 'intruders' (Van Gorp, 2005). Importantly, the modality (verbal or visual) in which these arguments are communicated matters for the way in which they are processed by audiences. Visuals are attention grabbing 
(Garcia \& Stark, 1991) and readily foster an emotional connection with the viewer (lyer, Webster, Hornsey, \& Vanman, 2014). However, visuals are often less explicit in their ability to relay meaning compared to the syntactic structure of a written text (Messaris \& Abraham, 2001). This article explicitly tests how the different qualities of visual and verbal media influence the selective exposure behaviour of citizens with opposing attitudes about contested issues.

Of course, polarized political journalism is not omnipresent. Most media outlets continue to favour balanced reporting covering competing perspectives of an issue, both in the U.S. and in other Western democracies (Prior, 2013; Umbricht \& Esser, 2014; Van Aelst et al., 2017). Moreover, observational and experimental research has shown that substantial numbers of media consumers purposely seek out balanced political information (Garrett \& Stroud, 2014; Metzger, Hartsell, \& Flanagin, 2015). However, relatively little research exists into the selection of balanced content in polarized contexts (Brenes Peralta, 2017). This study adds to the nascent literature on selective exposure to balanced content, and extends it by operationalizing balance in words and visuals.

In addition to a headline and visual, a news item is almost always accompanied by a source cue-an explicit indicator of the publishing outlet such as a small logo or a header. The ideological stance of this source can provide additional information to influence audiences' perceptions (Baum \& Groeling, 2009) and subsequent selection (lyengar \& Hahn, 2008). For instance, audience perceptions (Pew Research Center, 2014) show that Fox News is perceived as a regular source of anti-immigration coverage, The New York Times tends to adopt a proimmigration stance, whilst news agencies like Reuters provide a balanced perspective. Another key contribution of this study is examining how polarized source cues influence selective exposure alongside the visual and verbal content of the message itself.

To achieve these aims, we use concepts from selective exposure and visual communication theories operationalized in two experiments $(N=1068)$ using multiple stimulus exemplars and different political issues. By doing so, this study provides novel insights about (1) selective exposure to multimodal (text plus visual) content reflecting a fuller spectrum of political views, and (2) the relative strength of source cues and content cues in selection. We hope that these insights can help journalists and editors to develop engaging multimodal content whilst being aware of how they might contribute to a (de)polarized citizenry.

\subsection{Selective Exposure: Prevalence, Influences and Omissions}

This study relies on selective exposure-the tendency for citizens expose themselves to like-minded political content-as it's overarching theoretical approach. De- spite extensive research using a variety of methods, the jury is still out on the prevalence of this phenomenon (e.g., Arceneaux \& Johnson, 2013; Prior, 2013; Sears \& Freedman, 1967). More recent studies suggest that personalized echo chambers and filter bubbles are not as concerning as speculated (Nelson \& Webster, 2017; Zuiderveen Borgesius et al., 2016), since individuals also seek out counter-attitudinal news (Bakshy, Messing, \& Adamic, 2015; Stroud, 2011).

Concerns about the prevalence of attitudeconsistent selective exposure might further be tempered by considering balanced political content. From the demand side, media consumers often seek balanced news coverage provided by broadcast television (e.g., Prior, 2013). This is supported by experimental research showing that people select balanced content when given the opportunity (e.g., Feldman, Stroud, Bimber, \& Wojcieszak, 2013; Garrett \& Stroud, 2014). Other studies suggest this can be at least as often as proattitudinal content (Brenes Peralta, Wojcieszak, Lelkes, \& de Vreese, 2016).

In order to explain these patterns of selection, some scholars have argued that the prevalence of selective exposure depends on psychological characteristics that vary across individuals (e.g., motivations and attitude strength; Arceneaux \& Johnson, 2013; Garrett, 2009), as well as on certain characteristics of media messages (e.g., information utility or the evidence type; e.g., Hart et al., 2009).

This study addresses three omissions in prior research that fall into this latter category-message characteristics - to shed new light on this mixed literature. Namely: (1) a fixation on the written word has disregarded visuals as drivers for news selection; (2) a focus on one-sided (i.e., pro-attitudinal or counter-attitudinal) news to the neglect of balanced content; and (3) a failure to examine how source cues interact with the verbal and visual content of news items. These omissions are considered in more detail in the sections that follow.

\subsection{Visuals as a Cue to Selective Exposure}

Scholars have long considered visuals as an integral part of political communication (Barthes \& Heath, 1978), in part due to their effects on citizen's political perceptions and behaviour (Grabe \& Bucy, 2009; Graber, 1990). Indeed, recent studies have shown that the presence of news visuals can encourage the sharing and selection of news stories on social media (Casas \& Williams, 2019). However, to our knowledge, only a handful of studies have drawn a causal connection between visuals and news selection (Knobloch, Hastall, Zillmann, \& Callison, 2003; Wolf \& Grotta, 1985; Zillmann et al., 2001). Zillmann et al. (2001) showed that, compared to news reports without an image, stories accompanied by an image of victimization were read for longer and better remembered. As such, the presence of images can help citizens select into news. However, no studies have ex- 
amined the contribution of visuals to pro-attitudinal selective exposure, let alone considering how visuals interact with the headline of a typical news item. That is a key aim of this study.

In order to influence selective exposure, a news item would need to catch one's attention, encourage processing of the content, and relay meaning-with items whose central meaning being congenial to one's preferences likely to be selected more often. The contribution of words and visuals to this process can be illuminated by a fledgling body of research on multimodal framing (e.g., Dan, 2017; Geise \& Baden, 2015; Powell, Boomgaarden, De Swert, \& de Vreese, 2015). In their theoretical model of framing effects, Geise and Baden (2015) integrated insights from visual communication research (Barry, 1997; Garcia \& Stark, 1991; Paivio, 1991) with framing theory (Entman, 1993; Messaris \& Abraham, 2001) to articulate several propositions about how meaning is extracted from words and visuals: generally, visuals are eyecatching, perceived quickly, and exert an activating effect by fostering an emotional connection with the reader. By comparison, text is less salient but its syntactic structure lends itself to cognitive elaboration of a story's substance and, in turn, a more prescribed construction of meaning.

In order to test these propositions, empirical studies of multimodal media effects have adopted a common approach: systematic manipulation of whether the central message depicted by an image and text matches, or does not match (also known as congruence, or redundancy; e.g., Lang, 1995). Such mismatches are relatively com- mon in news media where busy editors select images in haste and from a limited pool, which can lead to haphazard pairings of image with text (Fahmy et al., 2014). Studies of visual-verbal congruence have, for example, used competing frames from war and conflict news (e.g., combining an image of threatening militants with a text about suffering victims) to broadly confirm the propositions of Geise and Baden (2015) about the distinct processing and effects of words and visuals in multimodal content (e.g., Boomgaarden, Boukes, \& Iorgoveanu, 2016; Powell et al., 2015; Powell, Boomgaarden, De Swert, \& de Vreese, 2018; Seo \& Dillard, 2016). In this study, we also adopt a manipulation of image-headline congruence to assess how the unique qualities of each modality contribute to selective exposure.

An important omission from this body of work, however, is the study of balanced content, which we know is attractive to audiences when selecting news content (Feldman et al., 2013). By definition, a balanced headline should present opposing sides of an issue. For instance, "The pros and cons of stricter gun laws in America", or "Syrian refugees: victims or threat?". Balance can also be depicted visually in the form of image juxtaposition. Placing two pictures next to each another can serve to emphasise the opposing stances on an issue by directly contrasting them (for an example, see Figure 1). This study adopts this approach to examine the selection of balanced visual and textual content and, to the best of our knowledge, is the first to investigate these types of balanced images that are sometimes seen in news media.
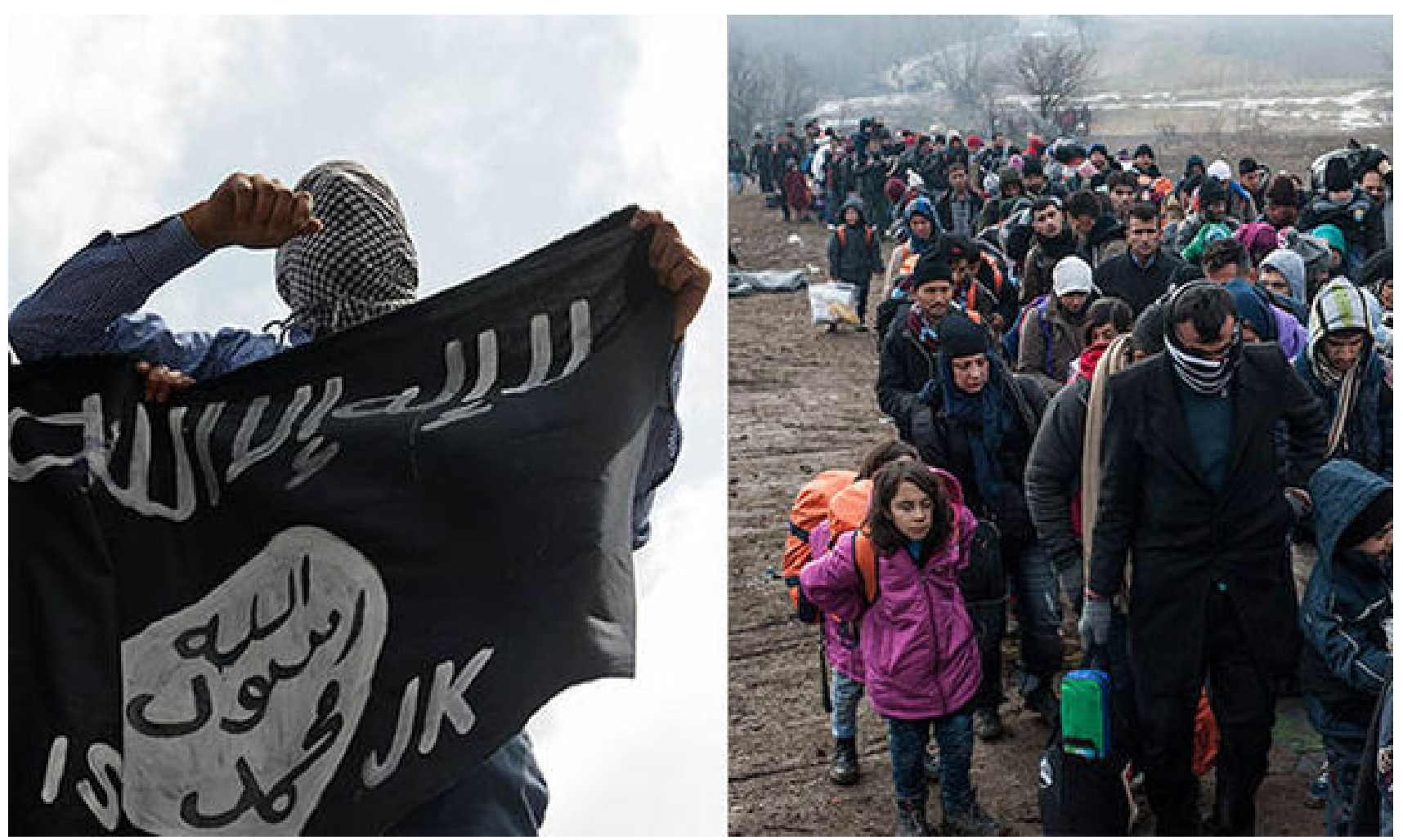

Figure 1. An example of image juxtaposition presenting opposing sides of the Syrian conflict. Note: this image was not used in the stimulus material-see Figure 2 and Figure 3 for stimulus examples (Logan, 2017). 
Through manipulating image-headline congruence, and by including balanced content, this study empirically examines multimodal selective exposure to a spectrum of political views. To do this we use headlines and images from news coverage of the Syrian refugee crisis and gun control combined in social media posts, so that the central meaning conveyed by the image and text either matches or does not match. Crucially, by analysing selection behaviour of those who support and oppose refugees and gun control, this design allows us to test whether images or headlines are a stronger driver of selective exposure. Due to the psychological 'power' of visuals, but their relative ambiguity compared to text, it is unclear which modality is the stronger determinant of selection behaviour. Moreover, due to relative dearth of research into balanced content, especially balance operationalised visually, we are unable to state definitive expectations about its selection. We therefore formulate the following research questions:

RQ1: Are news headlines or visuals more influential in driving pro-attitudinal selection of news items?

RQ2: How frequently are balanced headlines and visuals selected compared to pro-attitudinal and counterattitudinal headlines and visuals?

\subsection{The Impact of Source Cues on Selection}

Today's high-choice media environment makes it not only more possible for consumers to seek out news they might find agreeable but also provides an economic incentive for news organizations to cater to their viewers' political preferences (Mullainathan \& Shleifer, 2005). As such, one can be certain that purveyors of conservative leaning (e.g., Fox News) and liberal leaning media (e.g., The New York Times, NBC, The New Yorker, Slate; Pew Research Center, 2014) will continue to sustain a diet for polarized audience segments. Moreover, in keeping with the well-known "hostile media" phenomenon (Gunther, Christen, Liebhart, \& Chih-Yun Chia, 2001; Hansen \& Kim, 2011), partisans of either side are likely to impute bias to news sources that do not reflect their preferences. These perceived biases mean that indicators of source affiliation should provide a cue to selective exposure.

Selection does indeed seem to differ according to the affinity between a news organisation and the consumers' political views. In an experiment, lyengar and Hahn (2008) showed that conservatives preferred to select news attributed to Fox News and avoid liberal outlets, and vice versa for liberals, for a range of issues. However, citizens do sometimes select sources that cut across their political preferences (Prior, 2013). However, no studies have examined how source cues interact with the verbal and visual content of a news item itself to influence selection. That is a goal of this study.

To address this question, we included polarized source cues (The New York Times for liberal media; Fox News for conservative media; Reuters for neutral/bal- anced media) that matched the bias (pro/con/balanced for refugees and gun control) presented by the headlines of our news items. We considered this a logical approach since the textual headline typically takes priority over images in the editorial process, with visuals often selected as an afterthought (Fahmy et al., 2014). Based the evidence reviewed, we expect that the addition of source cues to a linked headline will reduce the influence of images in selective exposure. Formally we predict that:

$\mathrm{H} 1$ : The inclusion (compared to omission) of polarized news sources will strengthen the influence of headlines over images in news selection.

\section{Method}

To test the contribution of visuals, headlines and source cues to selection we rely on an experimental design. To ensure that the observed patterns hold across different political contexts and are therefore more reliable and generalizable, we conducted two identical experiments within different contexts. Study 1 tests news selection in the context of immigration in the U.S., drawing on news about the ongoing refugee crisis in Europe and the Middle East, with a focus on Syrian asylum seekers. Study 2 examines news selection processes in the context of gun ownership in U.S. This issue relates to the long-running debate regarding whether legal gun ownership is a right and necessity for personal protection or is the cause of numerous deadly mass shootings. Both issues are considered highly polarized topics and strongly related to political ideology.

\section{Study 1 Method: Selection of Partisan News about Immigration}

\subsection{Design}

In order to test the hypotheses, Study 1 applies an online survey-embedded experiment in the context of immigration in the U.S. The first experiment concerns a three within-subjects (visual bias: pro-immigration, i.e., immigrants as victims, versus anti-immigration, i.e., immigrants as intruders, versus balanced) by three within-subjects (headline bias: pro-immigration, i.e., immigrants as victims, versus anti-immigration, i.e., immigrants as intruders, versus balanced) by two betweensubjects (source cue: present versus absent) factorial design. To assess the selection of news items that were (in)congruent with participants' prior attitudes, each condition contained a randomly allocated sample of respondents that either supported or opposed refugees immigrating to the U.S.

\subsection{Sample}

U.S. participants were recruited in December 2016 via the Amazon Mechanical Turk (MTurk) crowd-sourcing 
platform. Previous research that used an MTurk sample has shown that replication studies and use of personality scales on MTurk yield comparable results to other participant pools (Buhrmester, Kwang, \& Gosling, 2011; Sprouse, 2011). In total, 534 respondents completed the survey in full and also answered an attention-check item correctly. The sample reflected a fair representation of the U.S. voting population for age $(M=38,37)$ and sex (47.8\% female). Regarding the distribution of education, $36.3 \%$ was lower educated, $12.2 \%$ was higher educated, and $51.5 \%$ had a moderate level of education.

\subsection{Procedure}

Participants accessed the survey-embedded experiment via an online link. After giving informed consent, participants answered an issue-attitude question that assessed their general support of the issue of migrants coming to the U.S. Participants were asked to indicate, on a scale from 1 to 7 (anchored strongly oppose and strongly support), how strongly they support or oppose refugees from Syria coming to the U.S. Respondents who answered this question with neither oppose or support were thanked and excluded from the survey, as we needed to identify those for whom the visual and textual bias were (in)congruent with their prior attitude. This item was followed by questions including respondents' demographics and political orientation. Afterwards, participants were informed that they would view multiple news items on the following pages.

The next page showed the nine stimulus news items (i.e., all visual and headline combinations, randomly ordered between participants) related to immigration to the U.S. Participants were instructed to imagine that they came across these news items in their everyday life (on for example their Facebook newsfeed or a news website) and were asked to select their top three news items they would like to view and leave the remaining items blank. After that, the same nine news items were each shown separately in a random order and participants were asked to rate the likelihood that they would select each item in their daily lives. Upon completion, participants were thanked and debriefed.

\subsection{Stimuli and Independent Variables}

The stimuli consisted of nine image-headline news items on immigration to the U.S. Both textual and visual stimuli elements were taken from media coverage of the Syrian refugee crisis.

For the final experiment, three pro-immigration (e.g., "Rejecting Syrian refugees goes against American ideals"), three anti-immigration (e.g., "Refugees not welcome here, governors of 16 states say"), and three balanced (e.g., "Syrian refugees: victims or threat?") headlines were selected. Based on a pilot experiment of numerous candidate headlines, the stimulus headlines were selected that most clearly conveyed the respective bias to respondents. Moreover, to maximize internal validity, headlines were chosen that were rated similarly on several factors known to influence media effects, including perceived arousal, salience, and complexity (e.g., Lang, 1995; Schuck \& de Vreese, 2006).

Because the balanced visuals showed a combination of pro- and anti-immigration in a single split image, more images had to be found than headlines. Six pro-immigration (e.g., a picture depicting a crying child pulled from a boat) and six anti-immigration (e.g., picture showing a refugee partaking in a violent protest) were selected. Just like the headlines, a pilot test on numerous candidate images was used to select the stimulus images that most strongly perceived as conveying the respective frame. Like the headlines, the images were also chosen based on their similar scores on perceived arousal, salience and complexity.

The images and headlines were then combined into nine news items comprising all possible matching and non-matching image-headline pairs (i.e., 1. Image pro $\times$ headline pro, 2 . Image pro $\times$ headline balanced, 3 . Image pro $\times$ headline anti, 4 . Image balanced $\times$ headline pro, 5. Image balanced $\times$ headline balanced, 6 . Image balanced $\times$ headline anti, 7 . Image anti $\times$ headline pro, 8. Image anti $\times$ headline balanced, and 9. Image anti $\times$ headline anti). The nine items were displayed in the form of a Facebook-style newsfeed (see Figure 2 for examples). The whole design was counterbalanced so that there was random allocation of the order in which the issues were presented, the position of the items on the screen, and the within-condition pairings of the different image and headline exemplars. Thus, multiple combinations per image-headline pairing were made to ensure that peculiarities of the specific combinations of headlines and visuals did not determine the selection of news items.

Dependent on the condition participants were allocated to, the news items either showed the source of the message or not. The source was always matched with the headline. When the headline was pro-immigration, The New York Times as a liberal information source was shown. For the anti-immigration headline, Fox News was added, and for the balanced headline Reuters was used (see Figure 3 for stimulus examples including sources, on the topic of gun control topic).

\subsection{Measures}

News selection. In order to measure whether participants would select a news item, based on the image and headline presented, two dependent measures were employed. First, when participants were shown the nine news items on one page, they were instructed to select the three news items that they would want to view. This selection variable provides an indication of whether respondents select pro-attitudinal items over a balanced or counter-attitudinal items based on the presented image or headline when there are multiple options (Feldman et al., 2013). 


\section{COGITATIO}

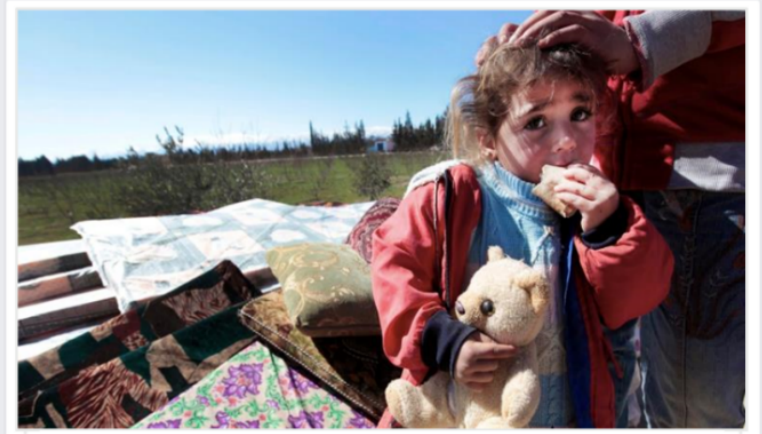

Rejecting Syrian refugees goes against American ideals

$$
\text { In Like Comment } \Rightarrow \text { Share }
$$

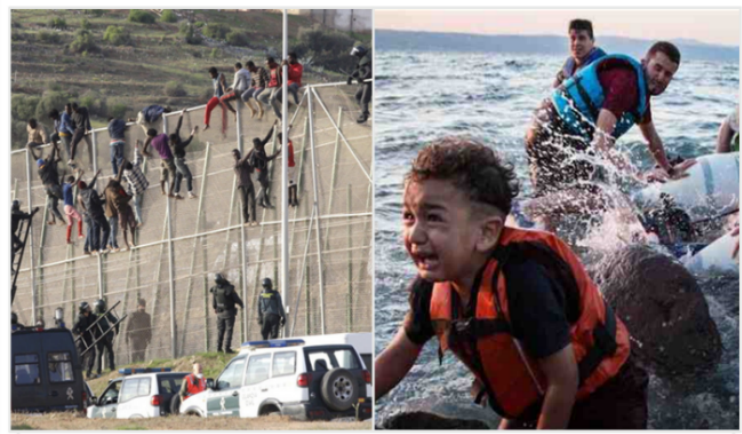

Syrian refugees: victims or threat?

$$
\text { Ilit Like Comment } \rightarrow \text { Share }
$$

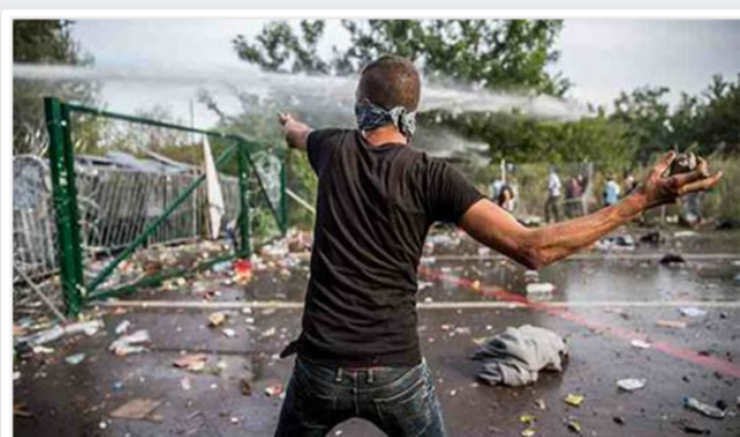

ISIS terrorists disguise as refugees

$$
\text { Ilin Like } \quad \text { Comment } \rightarrow \text { Share }
$$

Figure 2. Examples of three stimulus news items from Study 1 , for the refugee context, without sources. Notes: matching image-headline pairs are shown for the pro(top), balanced (middle) and anti-refugee (bottom) conditions. In total the stimulus newsfeed contained nine immigrations news items, comprising all possible matching and non-matching image-headline pairings. (c. The New York Times $1 \mathrm{hr} \cdot \mathrm{G}$

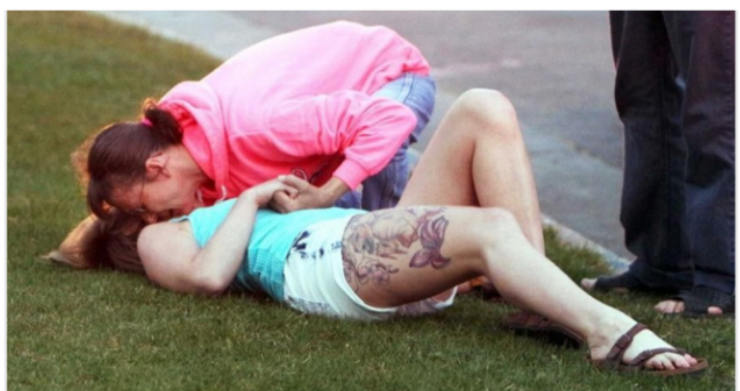

Stricter gun laws will prevent more mass shootings

In Like Comment $\Rightarrow$ Share

Reuters

$1 \mathrm{hr} \cdot \mathrm{C}$

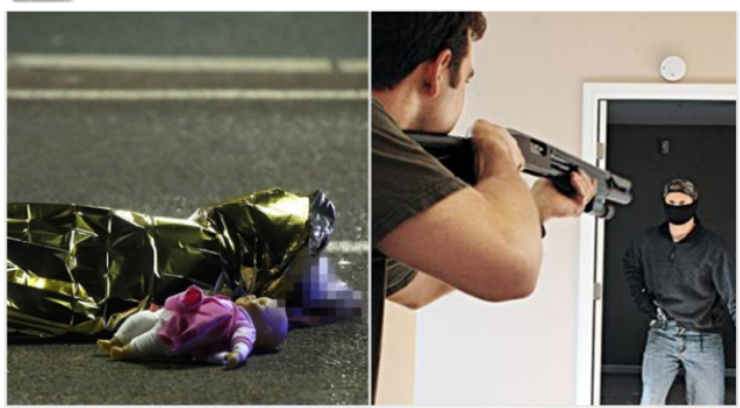

The pros and cons of stricter gun laws in America

II Like Comment $\Rightarrow$ Share

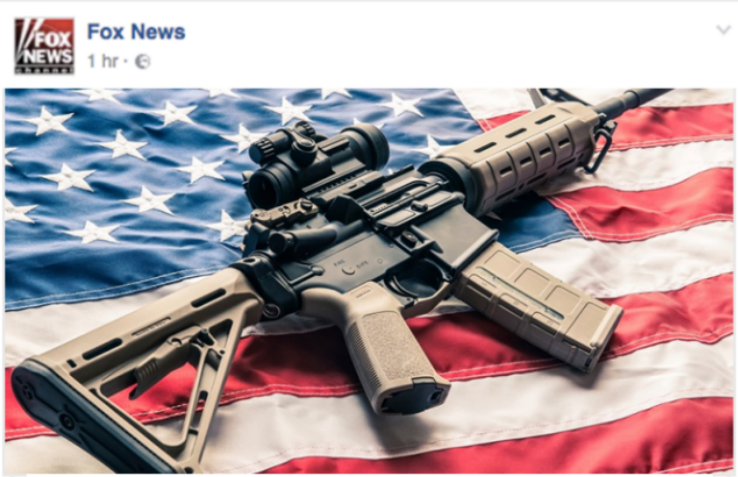

Stricter gun laws result in more deaths

It Like Comment $\rightarrow$ Share

Figure 3. Example of three stimulus news items from Study 2, for the gun context and including sources. Notes: matching image-headline pairs are shown for the pro (top), balanced (middle) and anti-gun laws (bottom) conditions. In total the stimulus newsfeed contained nine immigrations news items, comprising all possible matching and non-matching image-headline pairings. 
Second, the nine news items were then shown in a random order on separate pages, and participants were asked, thinking about their everyday life, how likely they would select each news item when they came across it on a scale from 0 "very unlikely" to 100 "very likely" (e.g., van der Meer, 2018). This measure indicates participants' likelihood of selecting news items with different combination of pro- or counter-attitudinal images with headlines.

\subsection{Analyses}

To be able to run the analyses we computed new conditions based on participants' attitudinal congruence with the image and headline. Images and headlines were coded as congruent if it was in line with participants' prior immigration attitudes and were coded incongruent if the message was counter to their views on immigration. Reported attitudinal scores ranging from one through three on the 7-point immigration scale were regarded as congruent with anti-immigration stimuli, and incongruent with the pro-immigration stimuli. Scores five through seven were interpreted as congruent with the pro-immigration stimuli and incongruent with the counter-immigration stimuli.

For the analysis, the data were stacked (wide-to-long) to deal with the within subject design. Thus, each judgment given by a respondent is treated as a single case. This approach was adopted to deal with the likelihood of selection rating measure which involved each respondent rating multiple news items, resulting in multiple observations per participant. Therefore, since final observations in the stacked data set are not independenti.e., each respondent rated nine news items and therefore appeared nine times in the dataset-responses are clustered within respondents. To control for this a multilevel approach with random intercept was applied. The use of a multilevel approach to control for this type of clustering has been applied in previous research, especially in quasi-experimental designs presenting multiple vignettes to respondents (for a comparable analytical approach see: Helfer \& Van Aelst, 2016; van der Meer, 2018). Regression analyses then tested if the different pairings of images and headline can explain selection behavior and likelihood ratings. For an alternative approach see Hainmueller, Hopkins and Yamamoto (2014).

\section{Study 1 Results}

\subsection{Visual and Verbal Cues in Polarized News Selection}

Multilevel regression analyses were used to address RQ1 regarding the power of polarized images and headlines in selective exposure, as well as RQ2 regarding the selection of balanced images and headlines. Figure 4 shows that, for both likelihood of viewing and the selection variables, pro-attitudinal and balanced headlines were strongest predictors of selection. The magnitude of these effects dwarfed that of the different image bias conditions. This was especially so for likelihood ratings. Interestingly, for news items with a balanced headline only, the bias of the attached image did influence the selection score-with pro-attitudinal images selected more frequently than balanced, which was selected more often than counter-attitudinal. These results are shown in Figure 4 and the full regression tables are shown in Table A1 and Table A2 in Appendix A.

Taken together, this answers RQ1 by showing that participants relied far more on headlines rather than images in their selective exposure to news. And, to answer $\mathrm{RQ} 2$, balanced headlines were selected equally as much as attitude congruent headlines, and much more so than attitude incongruent headlines. The effects of images only emerged when coupled with balanced textual content, further suggesting that images are a weaker cue to selection than headlines.

\subsection{Source Cues}

To test the additional effect of source cues on selective exposure to visual and verbal content, an interaction term was tested to see if the coefficients in the multilevel regression models differ by presence versus absence of source cues. As the source always matched the headline in terms of political stance, source-by-headline interactions were tested and several were subsequently observed (also visible in Figure 4). The multilevel regression analysis with likelihood ratings (Table B1 in Appendix B) showed that in the case of a congruent headline with an incongruent image and a congruent headline with a balanced image, the presence of source cues significantly increased the likelihood that a news item would be selected. Also, a news item with a balanced headline and a balanced image was more likely to be chosen. The multilevel logistic regression model for the selection variable showed comparable results. The inclusion of source cues strengthens the influence of headlines over images in news selection for the news items with a congruent headline and a congruent image, a congruent headline and an incongruent image, a balanced headline and a balanced image, and a balanced headline and a congruent image. When we changed the reference category to the balanced image and balanced headline conditions (as compared to the incongruentincongruent condition) we observed comparable results (Table B2 in Appendix B). In addition, a pattern of selective avoidance, rather than selective exposure, was observed since the inclusion of source cues decreased the likelihood that respondents selected news items with an incongruent headline and an incongruent image, an incongruent headline and a balanced image, and an incongruent headline and a congruent image. This supports $\mathrm{H} 1$ by showing that the influence of images in selection is diluted, and the influence of headlines is strengthened, with the addition of partisan source cues. Results can also be seen in Figure 4. 


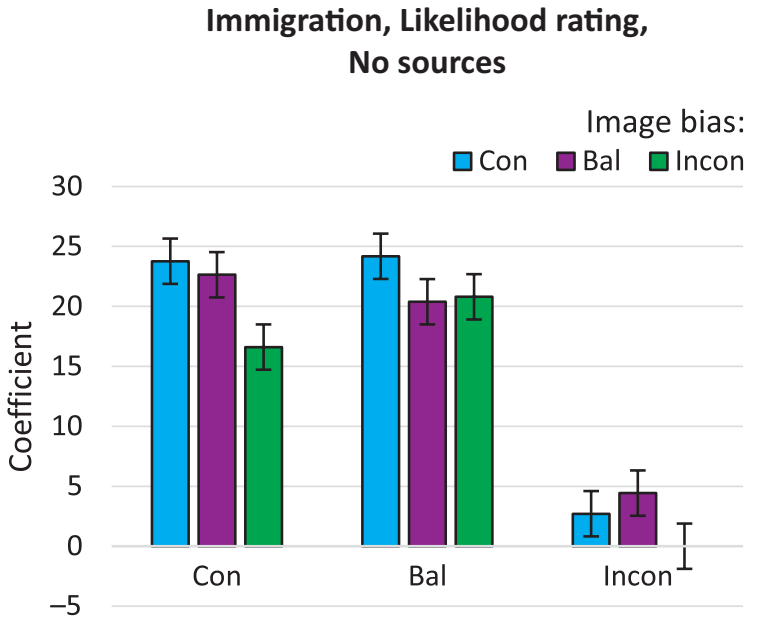

Headline bias

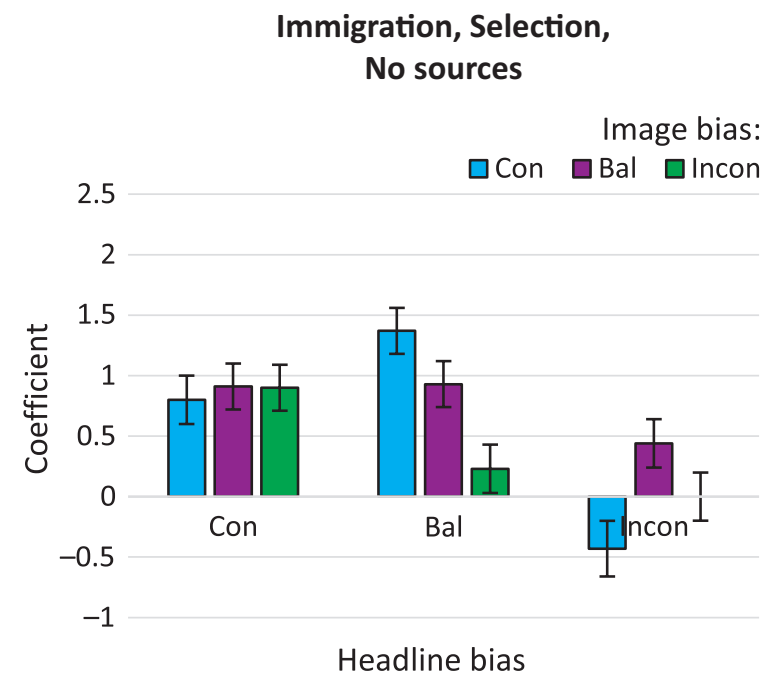

Immigration, Likelihood rating, With sources

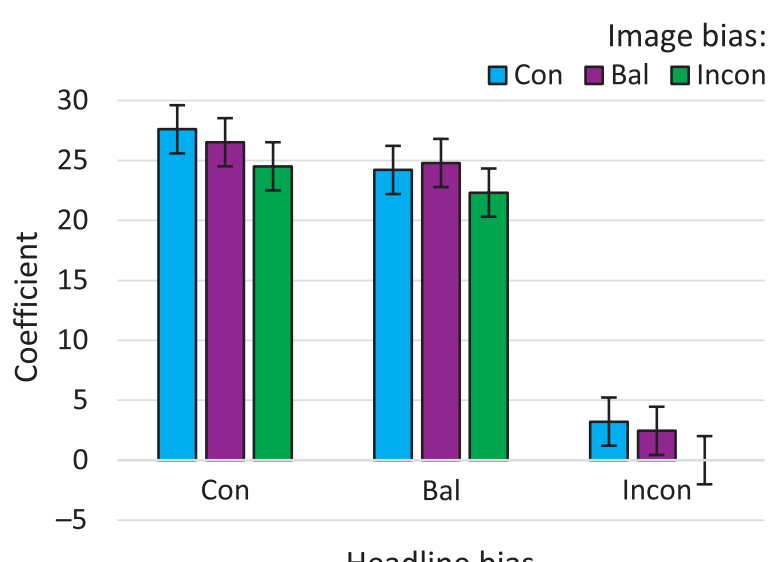

Immigration, Selection, With sources

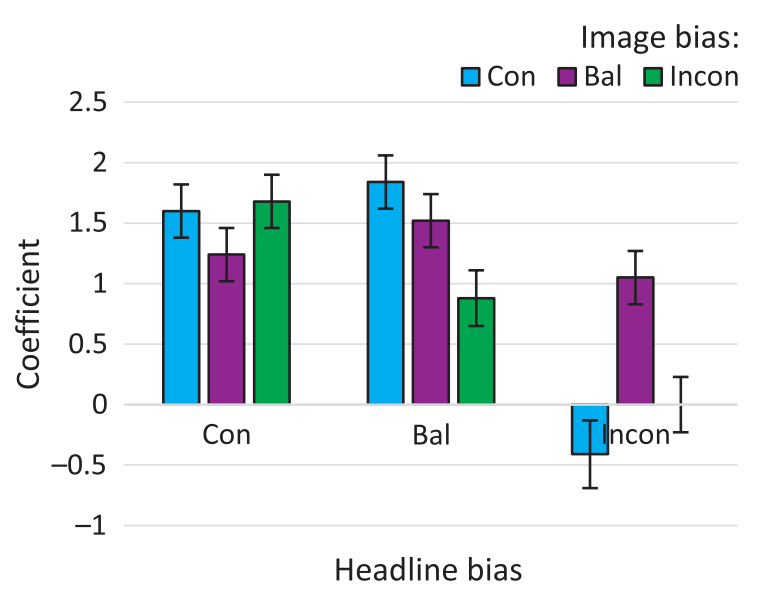

Figure 4. Coefficient plot comparing the selection of immigration news items with matching and non-matching headlines and images. Notes: Incon-Incon condition is used as the reference category. Regression coefficients and standard errors are plotted. Con = attitude congruent; $B a l=$ balanced; Incon = attitude incongruent.

\section{Study 2 Method: Selection of Partisan News about Gun Control}

\subsection{Design}

The experimental design applied in Study 2 is similar to the one in Study 1 . Study 2 aims to replicate the findings of Study 1 for the issue of gun control. The second experiment concerns a three within-subjects (visual bias: pro-gun control, i.e., victims of shootings due to gun ownership, versus anti-gun control, i.e., the legal right and to protect yourself, versus balanced) by three withinsubjects (headline bias: pro-gun control versus antigun control versus balanced) by two between-subjects (source cue: present versus absent) factorial design.

\subsection{Sample}

MTurk was used to recruit 534 U.S. participants. In total, the average age was 38.4 and $48 \%$ were female. Re- garding the distribution of education, 36\% was lower educated, $12 \%$ was higher educated, and $52 \%$ had a moderate level of education.

\subsection{Procedure}

The experiment followed exactly the same procedure as reported in Study 1.

\subsection{Independent Variables and Stimuli}

Similar to the manipulation of the news items in the first experiment, images and headlines were selected from media coverage on the ongoing debate about gun control in the U.S. Again, both images and headlines were selected based on pilot tests that indicated which images and headlines most strongly conveyed the desired bias. Moreover, images and headlines were chosen that were similarly rated on perceived arousal, salience, and complexity. Thus, images and texts were selected that were 
pro-gun control (e.g., headline: "Stricter gun laws will prevent more mass shootings"; image: picture showing a victim of mass shooting), anti-gun control (e.g., headline: "Stricter gun laws is treason"; image: picture showing someone protecting his family from a burglar with a weapon), and balanced (e.g., headline: "Opinions divided on gun control"; image: split image containing both pro- and anti-gun control images) (see Figure 3 for examples). Images and headlines were paired and counterbalanced in the same way as in the first experiment to obtain all combinations of congruent and incongruent pairs. The information source cue was manipulated in the same way as in Study 1.

\subsection{Measures and Analyses}

The measurement of the dependent variables and the analysis strategy for the second study was identical to the strategy reported under Study 1.
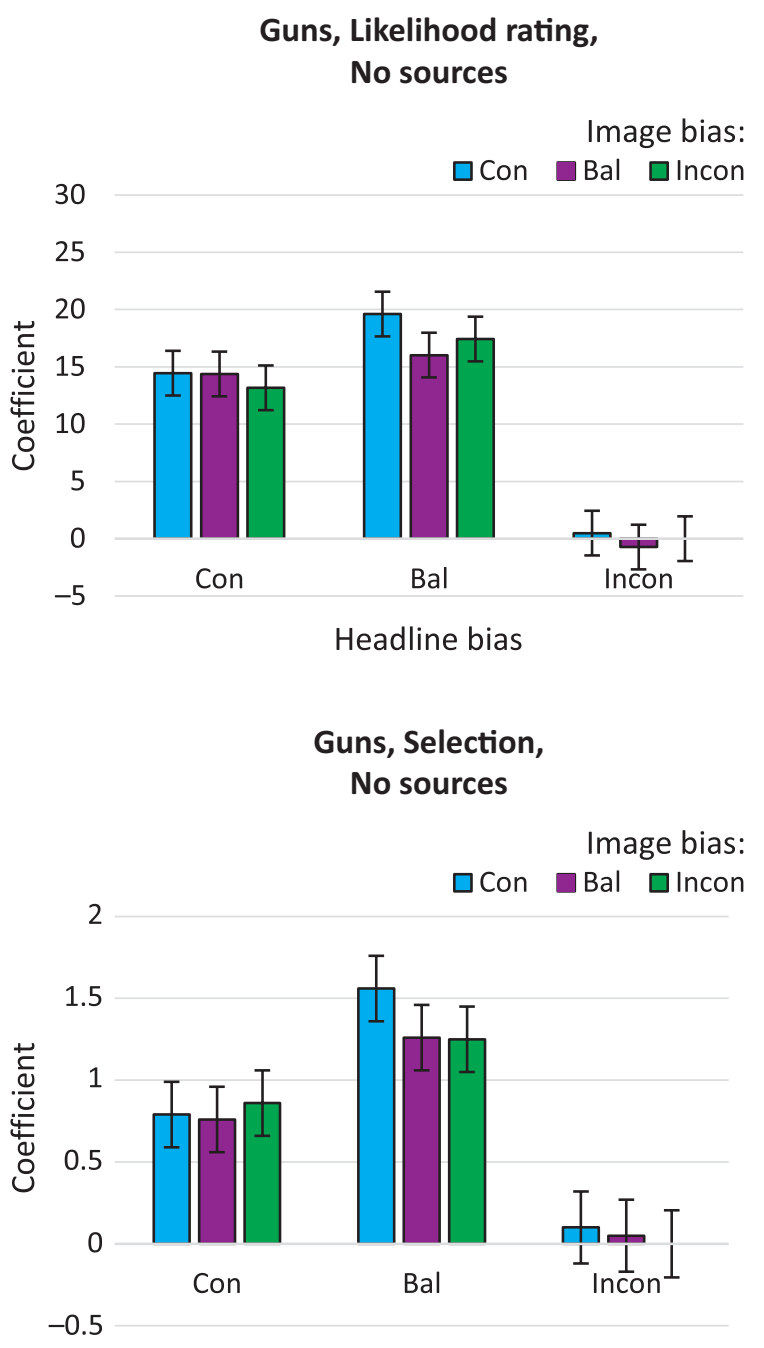

Headline bias

\section{Study 2 Results}

\subsection{Visual and Verbal Cues in Polarized News Selection}

Much the same pattern of results as in Study 1 were observed for Study 2-as shown in Figure 5. For both the likelihood ratings and the selection scores, headlines were dominant in driving selection, with no discernible influence of images. This outcome was even more clearcut than for Study 1. An interesting difference is that balanced headlines were selected more often that attitudecongruent headlines, for both the likelihood rating variable and selection scores. For full regression results see Table A3 and Table A4 in the Appendix A.

This provides the same answer to RQ1: headlines are more influential than images in news selection. Regarding RQ2 there indication that balanced headlines are preferred over attitude-congruent headlines, and attitude-congruent headlines were preferred over attitude-incongruent headlines.

\section{Guns, Likelihood rating,} With sources

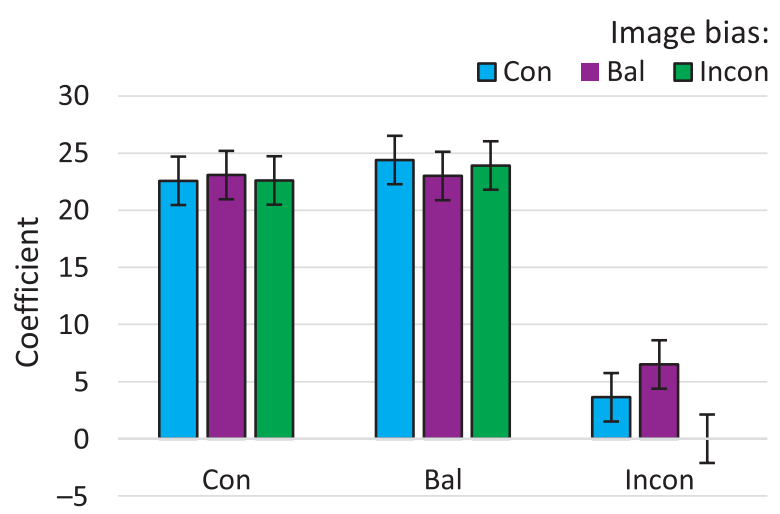

Headline bias

\section{Guns, Selection, With sources}

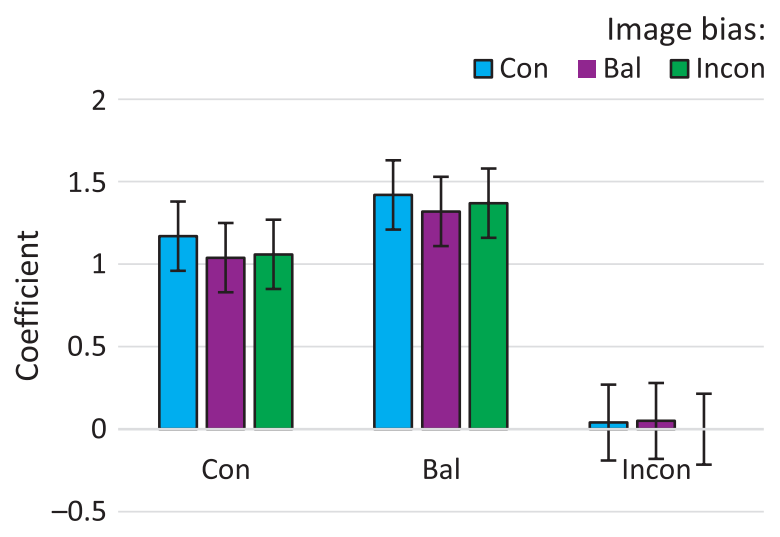

Headline bias

Figure 5. Coefficient plot comparing the selection of gun control news items with matching and non-matching headlines and images. Notes: Incon-Incon condition is used as the reference category. Regression coefficients and standard errors are plotted. Con = attitude congruent; $\mathrm{Bal}=$ balanced; Incon = attitude incongruent. 


\subsection{Source Cues}

Once again, the same pattern of results emerged for Study 2 as in Study 1. A significant source-by-headline interaction for likelihood scores shows that the addition of a source cue increased the influence of the headlines in selection (see Table B3 and Table B4 in the Appendix B). The likelihood ratings showed that participants were more likely to select attitude-congruent and balanced headlines with a matching source (in terms of political stance) than without, and were less likely to select an incongruent headline with a source than without. No effects were found for the categorical selection variable. In line with Study 1, these results provide support to $H 1$, that the influence of images in selection is diluted by the addition of source cues. These results are shown in Figure 5.

\section{Discussion}

This study set out to explore how images in news items contribute to partisan selective exposure. Until now, this topic has been neglected in studies of selective exposure which have focused entirely on text in headlines. Moreover, we sought to address how balanced visual and verbal cues influence selection, both with and without the addition of source cues belonging to partisan news organizations. Findings showed that headlines play a far greater role in guiding partisan selective exposure, with the influence of images being minimal. Moreover, balanced headlines were selected equally as often as proattitudinal headlines. And the addition of source cues increased the influence of headlines in selection, reducing the already small role played by images. These results were remarkably similar for both the issues of immigration and gun control in the U.S.

The dominance of headlines over images in partisan selective exposure was surprising considering the abundance of evidence from visual communication for the psychological "power" of news images (Garcia \& Stark, 1991; lyer et al., 2014). Instead, the findings show that the clear meaning delivered by the structured syntax of a text provides a less ambiguous and more informative cue to partisan news selection than images (Messaris \& Abraham, 2001). Therefore, despite pre-tests showing that the images did convey a clear meaning, a headline is the most decisive in determining citizens' selective exposure to like-minded political news. The importance of visuals in information processing and media effects (see e.g., Powell et al., 2015, 2018) but relative irrelevance compared to text in pro-attitudinal selective exposure is worthy of future research. This might fruitfully focus on whether emotional images can mitigate attitude polarization once citizens have already selected into partisan content.

The findings revealed an equally strong preference for balanced content as for pro-attitudinal news. This is in line with recent studies suggesting that citizens' self- selection into ideological echo chambers is not as prevalent as some had initially suspected (Nelson \& Webster, 2017; Prior, 2013). That said, participants in this study did resolutely avoid cross-cutting selection of counterattitudinal headlines (Garrett, 2009). Another novel addition of this study was to consider visual balance by presenting two sides of an issue via juxtaposed news images. Although images were a relatively weak cue to selection overall, an effect of image bias did emerge when they were accompanied by balanced headlines about the immigration issue. Attitude congruent, balanced, and attitude incongruent images were selected in this order, respectively, suggesting that visual balance is discernible to citizens when accompanied by a balanced headline. Future research should further investigate whether audiences value visual balance as an attractive and informative quality of today's increasingly visual news media.

Source cues belonging to partisan news organisations played a significant role in selective exposure. The addition of Fox News, Reuters and The New York Times logos to news items increased the selection of ideologically matched headlines compared to images. In line with previous findings (lyengar \& Hahn, 2008), source cues especially bolstered the selection of pro-attitudinal headlines. This suggests that these logos provide a simple and effortless decision heuristic that do foster selection into ideologically divided camps. That said, even with source cues present, balanced selection remained highly prevalent. This is a reassuring but somewhat unexpected finding, since, in light of hostile media theory (Hansen \& Kim, 2011), one would expect a more negative perception and thereby reduced selection of all non-congenial news media. Taken together, the magnitude of effects produced by the three independent variables in this study suggests a clear hierarchy of influence over partisan selective exposure: headline bias, source cues, and, finally, image bias.

There are a number of reasons to be confident about the validity of our conclusions. Multiple different headline and image exemplars were used in each condition, with their pairings counterbalanced, meaning that the results are not a product of stimulus peculiarities. Additionally, all stimuli were carefully pre-tested to ensure they depicted the intended bias and to match them for potentially confounding factors-perceived arousal, salience and complexity. Furthermore, our multiple issue approach increases generalizability, whilst stimulus presentation in a Facebook-style newsfeed heightens external validity. Finally, we observed similar results when party affiliation (Republican, Democrat) was used in the analyses instead of prior issue attitudes.

There are, however, notable limitations to this study. First, regarding ecological validity, all news items presented to participants were about the same issue, whereas a real social media timeline would contain items about a range of issues, as well as posts from one's friendship network. Future studies should study visuals in selective exposure using a richer media setting. Sep- 
arately, our selection environment was limited to one page of news items that were rated or selected. A more externally valid approach would be to create a navigable online 'magazine' through which participants are free to browse with their selection behaviour unobtrusively tracked (e.g., Zillmann et al., 2001). Another important limitation is that, in order to fully disentangle the effects of images from that of headlines, one would need to include conditions in which images and headlines were shown in isolation, and then compare this with selection behaviour in combined image-headline conditions. This was, however, beyond the scope of the present study and is being tackled in other research efforts (Powell, Hameleers, \& van der Meer, 2019). In addition, in this study we only manipulated the presence of source cues linked to the headlines of our news items. This means that we cannot ascertain whether news visuals do play a role in selection if they are paired with a certain source cue. Future studies should seek to include all possible pairings of visual and verbal content and source cues. Moreover, our source cues were only drawn from only three news organizations, and a broader array of sources is needed in future studies. Finally, it is important that future research expands this work beyond the context of Facebook to systematically study different media and various platforms. To illustrate: in different social media platforms where images or video are the main focus (such as Instagram or Snapchat), images may play a different, potentially more central role. Also, images and text are not necessarily always separable, for example in political memes. Ideally such work would combine content analysis to more comprehensively examine the intended function of visuals in news and social media-i.e., to simply capture attention, or to convey meaning-with experiments into news selection and attitude effects.

The theoretical implications of this study are clear. It is the first to connect theories of partisan selective exposure and visual communication-an important contribution given today's high-choice, highly fragmented and increasingly visual media environment. The observed dominance of text over visuals is somewhat reassuring in the sense that citizens do make the (albeit small) effort to process the meaning of a news headline instead of being drawn in by attention-grabbing visuals. However, this does imply that pictures may not serve as a means to draw citizens into counter-attitudinal news and thereby encourage attitudinal depolarization. Ultimately, more studies are required to examine the extent to which visuals fulfil a democratic good of encouraging selection into political and cross-cutting news, and whether visuals might help nullify any polarizing effects produced by selective exposure. More broadly, the inclusion of balanced content and source cues in this study helps quantify the relative influence of various message cues that can drive partisan news selection: headlines lead the way in determining partisan selective exposure, followed by the ideological affiliation of source cues, and, lastly, the contribution of images. The smaller effect of ideologically polarized news sources compared to textual content might be considered normatively encouraging. This chimes with the more optimistic findings of recent research showing preferences for balanced content (Brenes Peralta et al., 2016; Van Aelst et al., 2017) and should be supplemented by future studies into how different message characteristics are processed by viewers, and the way in which this is influenced by individual psychological factors.

This study lends practical guidance to news organisations and journalists alike. First, journalists should be aware that audiences will follow headlines rather than images in selecting news that matches their political views. This is in line with the traditional editorial priority for text, but presents an interesting conundrum as modern newsrooms become increasingly focused on the visual. Second, news organisations should strive for the journalistic ideal of balanced content since this is at least as attractive to audiences as congenial polarized content. This is heartening since headlines about both sides of an issue or posing an open question can therefore serve as 'click bait' without journalists needing to resort to being negative, extreme or pro-attitudinal. Third, news organisations who actively make their logos visible alongside their content can expect increased selection from all audience segments, but especially from their loyal readership.

To conclude, this study provides clear evidence of the role of visuals in partisan selective exposure. The text of headlines leads the way in citizens' decision to select congenial and balanced news, with source cues belonging to news outlets playing a contributing role. Images proved to be a more ambiguous indicator of the ideological stance of a news item and, in turn, played a minimal role in news selection. These findings go beyond previous studies by establishing a multimodal understanding of selective exposure to a fuller spectrum of political views. In doing so they provide clear guidance to journalists developing engaging content whilst being aware of how they might contribute to a (de)polarized citizenry.

\section{Acknowledgments}

We would like to thank Jelle Boumans and Guus Bartholomé for providing the table football table that assisted with the completion of this article. Special thanks to Guus for letting his opponents enjoy many victories at his expense.

\section{Conflict of Interests}

The authors declare no conflict of interests.

\section{References}

Arceneaux, K., \& Johnson, M. (2013). Changing minds or changing channels? Partisan news in an age of choice. Chicago, MI: University of Chicago Press. 
Bakshy, E., Messing, S., \& Adamic, L. (2015). Exposure to ideologically diverse news and opinion on Facebook. Science, 348(6239), 1130-1132.

Barry, A. M. (1997). Visual intelligence: Perception, image, and manipulation in visual communication. Albany, NY: State University of New York Press.

Barthes, R., \& Heath, S. (1978). Image-music-text. (1st ed.). New York, NY: Hill and Wang.

Baum, M. A., \& Groeling, T. (2009). Shot by the messenger: Partisan cues and public opinion regarding national security and war. Political Behavior, 31(2), 157-186.

Boomgaarden, H., Boukes, M., \& lorgoveanu, A. (2016). Image versus text: How newspaper reports affect evaluations of political candidates. International Journal of Communication, 10, 2529-2555.

Brenes Peralta, C., Wojcieszak, M., Lelkes, Y., \& de Vreese, C. (2016). Selective exposure to balanced content and evidence type: The case of issue and non-issue publics about climate change and health care. Journalism \& Mass Communication Quarterly, 94(3), 833-861.

Brenes Peralta, C. M. (2017). Two sides to every story: Causes and consequences of selective exposure to balanced political information (Doctoral dissertation). Faculty of Social and Behavioural Sciences, Amsterdam School of Communication Research, Amsterdam, Netherlands. Retrieved from https://dare.uva.nl/search?identifier $=5 \mathrm{cc} 8 \mathrm{~b} 72 \mathrm{e}-$ 8911-47c6-9a40-80e10b9e91fa

Buhrmester, M., Kwang, T., \& Gosling, S. D. (2011). Amazon's Mechanical Turk: A new source of inexpensive, yet high-quality, data? Perspectives on Psychological Science, 6(1), 3-5.

Casas, A., \& Williams, N. W. (2019). Images that matter: Online protests and the mobilizing role of pictures. Political Research Quarterly, 72(2), 360-375.

Dan, V. (2017). Integrative framing analysis: Framing health through words and visuals. New York, NY: Routledge.

Entman, R. M. (1993). Framing: Toward clarification of a fractured paradigm. Journal of Communication, 43(4), 51-58.

Fahmy, S., Bock, M. A., \& Wanta, W. (2014). Visual communication theory and research: A mass communication perspective. New York, NY: Palgrave Macmillan.

Feldman, L., Stroud, N. J., Bimber, B., \& Wojcieszak, M. (2013). Assessing selective exposure in experiments: The implications of different methodological choices. Communication Methods and Measures, 7(3), 198-220.

Garcia, M., \& Stark, P. (1991). Eyes on the news. St Petersburg, FL: Poynter Institute for Media Studies.

Garrett, R. K. (2009). Politically motivated reinforcement seeking: Reframing the selective exposure debate. Journal of communication, 59(4), 676-699.

Garrett, R. K., \& Stroud, N. J. (2014). Partisan paths to exposure diversity: Differences in pro and counter at- titudinal news consumption. Journal of Communication, 64(4), 680-701.

Geise, S., \& Baden, C. (2015). Putting the image back into the frame: Modeling the linkage between visual communication and frame-processing theory. Communication Theory, 25(1), 46-69.

Grabe, M. E., \& Bucy, E. P. (2009). Image bite politics: News and the visual framing of elections. New York, NY: Oxford University Press.

Graber, D. (1990). Seeing is remembering: How visuals contribute to learning from television news. Journal of Communication, 40(3), 134-155.

Gunther, A. C., Christen, C. T., Liebhart, J. L., \& ChihYun Chia, S. (2001). Congenial public, contrary press, and biased estimates of the climate of opinion. Public Opinion Quarterly, 65(3), 295-320.

Hainmueller, J., Hopkins, D. J., \& Yamamoto, T. (2014). Causal inference in conjoint analysis: Understanding multidimensional choices via stated preference experiments. Political Analysis, 22(1), 1-30.

Hansen, G. J., \& Kim, H. (2011). Is the media biased against me? A meta-analysis of the hostile media effect research. Communication Research Reports, 28(2), 169-179.

Hart, W., Albarracín, D., Eagly, A. H., Brechan, I., Lindberg, M. J., \& Merrill, L. (2009). Feeling validated versus being correct: a meta-analysis of selective exposure to information. Psychological Bulletin, 135(4), 555.

Helfer, L., \& Van Aelst, P. (2016). What makes party messages fit for reporting? An experimental study of journalistic news selection. Political Communication, 33(1), 59-77. https://doi.org/10.1080/10584609. 2014.969464

Iyengar, S., \& Hahn, K. S. (2008). Red media, blue media: Evidence of ideological selectivity in media use. Journal of Communication, 59(1), 19-39.

Iyer, A., Webster, J., Hornsey, M. J., \& Vanman, E. J. (2014). Understanding the power of the picture: The effect of image content on emotional and political responses to terrorism. Journal of Applied Social Psychology, 44(7), 511-521.

Knobloch, S., Hastall, M., Zillmann, D., \& Callison, C. (2003). Imagery effects on the selective reading of internet newsmagazines. Communication Research, 30(1), 3-29.

Lang, A. (1995). Defining audio/video redundancy from a limited capacity information processing perspective. Communication Research, 22(1), 86-115.

Logan, R. (2017). ISIS recruiting refugees by offering '\$1000 and safe passage to Europe'. Express. Retrieved from https://www.express.co.uk/news/ world/763849/ISIS-recruiting-refugees-by-offering1000-and-safe-passage-to-Europe

Messaris, P., \& Abraham, L. (2001). The role of images in framing news stories. In S. D. Reese, O.H. Gandy, \& A. E. Grant (Eds.), Framing public life (pp. 215-226). Mahwah, NJ: Erlbaum.

Metzger, M. J., Hartsell, E. H., \& Flanagin, A. J. (2015). Cog- 
nitive dissonance or credibility? A comparison of two theoretical explanations for selective exposure to partisan news. Communication Research, 2015, 1-26. https://doi.org/10.1177/0093650215613136

Mullainathan, S., \& Shleifer, A. (2005). The market for news. The American Economic Review, 95(4), 1031-1053.

Nelson, J. L., \& Webster, J. G. (2017). The myth of partisan selective exposure: A portrait of the online political news audience. Social Media + Society, 3(3), 1-13. https://doi.org/10.1177/2056305117729314

Paivio, A. (1991). Images in mind: The evolution of a theory. New York, NY: Harvester Wheatsheaf.

Pew Research Center. (2014). Political polarization and media habits. Pew Research Center. http://www. journalism.org/2014/10/21/political-polarizationmedia-habits

Powell, T. E., Boomgaarden, H. G., De Swert, K., \& de Vreese, C. H. (2015). A clearer picture: The contribution of visuals and text to framing effects. Journal of Communication, 65(6), 997-1017.

Powell, T. E., Boomgaarden, H. G., De Swert, K., \& de Vreese, C. H. (2018). Framing fast and slow: A dual processing account of multimodal framing effects. Media Psychology, 22(4), 1-29.

Powell, T. E., Hameleers, M., \& van der Meer, G. L. A. (2019). Can I picture myself selecting political news? The contribution of visuals to the selection and persuasiveness of the political news in information-rich media settings. Manuscript submitted for publication.

Prior, M. (2013). Media and political polarization. Annual Review of Political Science, 16(1), 101-127.

Schuck, R. T., \& de Vreese, C. H. (2006). Between risk and opportunity: News framing and its effects on public support for EU enlargement. European Journal of Communication, 21(1), 5-31.

Sears, D. O., \& Freedman, J. L. (1967). Selective exposure to information: A critical review. Public Opinion Quarterly, 31(2), 194-213.

Seo, K., \& Dillard, J. (2016). The persuasive effects of two stylistic elements: Framing and imagery. Communication Research, 2016, 1-17.
https://doi.org/10.1177\%2F0093650215626979

Sprouse, J. (2011). A validation of Amazon Mechanical Turk for the collection of acceptability judgments in linguistic theory. Behavior Research Methods, 43(1), 155-167.

Stroud, N. J. (2010). Polarization and partisan selective exposure. Journal of Communication, 60(3), 556-576.

Stroud, N. J. (2011). Niche news: The politics of news choice. New York, NY: Oxford University Press.

Sunstein, C. R. (2009). Republic.com 2.0. Princeton, NJ: Princeton University Press.

Umbricht, A., \& Esser, F. (2014). Changing political news? Long-term trends in American, British, French, Italian, German, and Swiss print media reporting. In Political Journalism in Transition: Western Europe in a Comparative Perspective (pp. 195-217). London: I.B. Tauris.

Van Aelst, P., Strömbäck, J., Aelberg, T., Esser, F., de Vreese, C., Matthes, J., . . . Stanyer, J. (2017). Political communication in a high-choice media environment: A challenge for democracy? Annals of the International Communication Association, 41(1), 3-27. https://doi.org/10.1080/23808985.2017.1288551

van der Meer, T. G. (2018). Public frame building: The role of source usage in times of crisis. Communication Research,45(6), 956. https:// doi.org/10.1177\%2F0093650216644027

Van Gorp, B. (2005). Where is the frame? Victims and intruders in the Belgian press coverage of the asylum issue. European Journal of Communication, 20(4), 484-507.

Wolf, R., \& Grotta, G. L. (1985). Images: A question of readership. Newspaper Research Journal, 6(2), 30-36.

Zillmann, D., Knobloch, S., \& Yu, H.-S. (2001). Effects of photographs on the selective reading of news reports. Media Psychology, 3(4), 301-324.

Zuiderveen Borgesius, F., Trilling, D., Möller, J., Bodó, B., de Vreese, C., \& Helberger, N. (2016). Should we worry about filter bubbles? Internet Policy Review, 5(1). https://doi.org/10.14763/2016.1.401

\section{About the Authors}

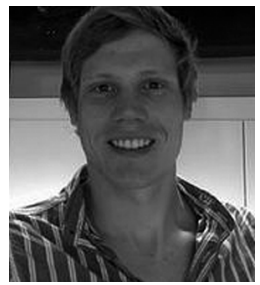

Thomas E. Powell is a Scientist at The Netherlands Organisation for Applied Scientific Research (TNO). This article was written when he was Assistant Professor at the University of Amsterdam, where he obtained his PhD in Political Communication. He obtained a BSc in Psychology at Durham University, an MSc in Neuroimaging at Bangor University and has worked at the University of Cambridge. His research interests include media effects, framing, visual communication and applied behavioural/cognitive science. 


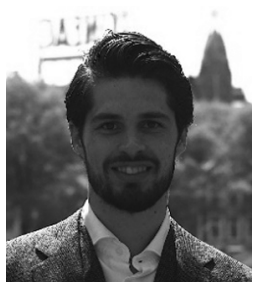

Toni G. L. A. van der Meer is Assistant Professor in Corporate Communication at the Amsterdam School of Communication Research (ASCoR), Amsterdam, The Netherlands. His research interests include crisis communication, media coverage of negative incidents, news media bias, and mediatization.

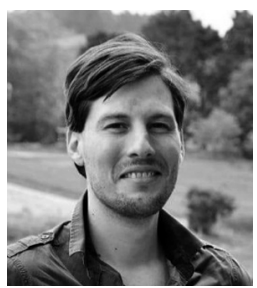

Carlos Brenes Peralta is a Postdoctoral Researcher in public opinion at the Center for Research and Political Studies of the University of Costa Rica. This article was written when he was a lecturer at the University of Amsterdam, where he obtained his PhD in Political Communication. He obtained a BSc and a Licentiate in Psychology at the University of Costa Rica and a MSc in Social Research at VU University Amsterdam. 


\section{Appendix}

\section{Appendix A}

Table A1. Refugees context, multilevel models explaining peoples' likelihood of viewing a news item, source and no source.

\begin{tabular}{llcc}
\hline & News item type & \multicolumn{2}{c}{ Source information included } \\
\hline Image & Headline & Without source information & With source information \\
\hline Congruent & Congruent & $23.77(1.89)^{* * *}$ & $27.60(2.01)^{* * *}$ \\
Congruent & Incongruent & $2.71(1.89)$ & $3.22(2.01)$ \\
Congruent & Balanced & $24.19(1.89)^{* * *}$ & $24.21(2.01)^{* * *}$ \\
Balanced & Congruent & $22.64(1.89)^{* * *}$ & $26.52(2.01)^{* * *}$ \\
Balanced & Incongruent & $4.43(1.89)^{* *}$ & $2.45(2.01)$ \\
Balanced & Balanced & $20.39(1.89)^{* * *}$ & $24.79(2.01)^{* * *}$ \\
Incongruent & Congruent & $16.61(1.89)^{* * *}$ & $24.51(2.01)^{* * *}$ \\
Incongruent & Balanced & $20.80(1.89)^{* * *}$ & $22.32(2.01)^{* * *}$ \\
\hline & Constant & $39.74(1.82)^{* * *}$ & $39.41(1.80)^{* * *}$ \\
& ICC level & .462 & .377 \\
\hline
\end{tabular}

Notes: ${ }^{* *} \mathrm{p}<.01 .{ }^{* * *} \mathrm{p}<.001$. Reference category is news item with incongruent headline and incongruent image. Cells contain unstandardized regression coefficients with standard errors. IIC = Intraclass correlation coefficient; LL = Log likelihood.

Table A2. Refugees context, logistic multilevel models explaining peoples' selection of a news item, source and no source.

\begin{tabular}{llcc}
\hline & News item type & \multicolumn{2}{c}{ Source information included } \\
\hline Image & Headline & Without source information & With source information \\
\hline Congruent & Congruent & $.81(.20)^{* * *}$ & $1.60(.22)^{* * *}$ \\
Congruent & Incongruent & $-.43(.22)^{*}$ & $-.412(.28)$ \\
Congruent & Balanced & $1.37(.19)^{* * *}$ & $1.84(.22)^{* * *}$ \\
Balanced & Congruent & $.91(.19)^{* * *}$ & $1.24(.22)^{* * *}$ \\
Balanced & Incongruent & $.44(.20)$ & $1.05(.22)^{* * *}$ \\
Balanced & Balanced & $.93(.19)^{* * *}$ & $1.52(.22)^{* * *}$ \\
Incongruent & Congruent & $.90(.19)^{* * *}$ & $1.68(.22)^{* * *}$ \\
Incongruent & Balanced & $.23(.21)$ & $.88(.23)^{* * *}$ \\
\hline & Constant & $-1.31(.15)^{* * *}$ & $-1.85(.18)^{* * *}$ \\
& ICC level & $8.34 \mathrm{e}-26$ & $5.34 \mathrm{e}-25$ \\
& LL full model & -1474.95 & -1407.93
\end{tabular}

Notes: ${ }^{*} \mathrm{p}<.05 . ;{ }^{* * *} \mathrm{p}<.001$. Reference category is news item with incongruent headline and incongruent image. Cells contain unstandardized regression coefficients with standard errors. IIC = Intraclass correlation coefficient; LL = Log likelihood. 
Table A3. Gun control context, multilevel models explaining peoples' likelihood of viewing a news item, source and no source.

\begin{tabular}{llcc}
\hline & News item type & \multicolumn{2}{c}{ Source information included } \\
\hline Image & Headline & Without source information & With source information \\
\hline Congruent & Congruent & $14.45(1.95)^{* * *}$ & $22.58(2.17)^{* * *}$ \\
Congruent & Incongruent & $.49(1.95)$ & $3.63(2.11)^{\dagger}$ \\
Congruent & Balanced & $19.61(1.95)^{* * *}$ & $24.40(2.11)^{* * *}$ \\
Balanced & Congruent & $14.38(1.95)^{* * *}$ & $23.08(2.12)^{* * *}$ \\
Balanced & Incongruent & $-.74(1.95)$ & $6.50(2.12)^{* *}$ \\
Balanced & Balanced & $16.03(1.95)^{* * *}$ & $23.01(2.12)^{* * *}$ \\
Incongruent & Congruent & $13.17(1.95)^{* * *}$ & $22.61(2.12)^{* * *}$ \\
Incongruent & Balanced & $17.43(1.95)^{* * *}$ & $23.92(2.12)^{* * *}$ \\
\hline & Constant & $43.97(1.95)^{* * *}$ & $39.15(1.89)^{* * *}$ \\
& ICC level & .433 & .364 \\
\hline
\end{tabular}

Notes: $\dagger p<.10 ;{ }^{* * *} p<.001$. Reference category is news item with incongruent headline and incongruent image. Cells contain unstandardized regression coefficients with standard errors. IIC = Intraclass correlation coefficient; LL = Log likelihood.

Table A4. Gun control context, logistic multilevel models explaining peoples' selection of a news item, source and no source.

\begin{tabular}{llcc}
\hline & News item type & \multicolumn{2}{c}{ Source information included } \\
\hline Image & Headline & Without source information & With source information \\
\hline Congruent & Congruent & $.79(.20)^{* * *}$ & $1.17(.21)^{* * *}$ \\
Congruent & Incongruent & $.10(.22)$ & $.039(.23)$ \\
Congruent & Balanced & $1.6(.20)^{* * *}$ & $1.42(.20)^{* * *}$ \\
Balanced & Congruent & $.76(.20)^{* * *}$ & $1.04(.21)^{* * *}$ \\
Balanced & Incongruent & $.05(.22)$ & $.05(.23)$ \\
Balanced & Balanced & $1.26(.20)^{* * *}$ & $1.32(.21)^{* * *}$ \\
Incongruent & Congruent & $.86(.20)^{* * *}$ & $1.06(.21)^{* * *}$ \\
Incongruent & Balanced & $1.25(.20)^{* * *}$ & $1.37(.21)^{* * *}$ \\
\hline & Constant & $-1.48(.16)^{* * *}$ & $-1.60(.17)^{* * *}$ \\
& ICC level & $1.15 \mathrm{e}-15$ & $1.74 \mathrm{e}-16$ \\
& LL full model & -1467.48 & -1436.49 \\
\hline
\end{tabular}

Notes: ${ }^{* *} \mathrm{p}<.001$. Reference category is news item with incongruent headline and incongruent image. Cells contain unstandardized regression coefficients with standard errors. IIC = Intraclass correlation coefficient; LL = Log likelihood. 


\section{Appendix $B$}

Table B1. Refugees context, multilevel models explaining peoples' likelihood of viewing and selection of a news items, interacted with source information.

\begin{tabular}{|c|c|c|c|c|}
\hline \multicolumn{2}{|c|}{ News item type } & \multirow[b]{2}{*}{ Interaction source information } & \multicolumn{2}{|c|}{ Dependent variable } \\
\hline Image & Headline & & Likelihood rating & Selection \\
\hline Congruent & Congruent & & $23.77(1.94)^{* * *}$ & $.80(.20)^{* * *}$ \\
\hline Congruent & Congruent & With source info & $3.83(2.76)$ & $.80(.29)^{* *}$ \\
\hline Congruent & Incongruent & & $2.71(1.94)$ & $-.43(.23)^{*}$ \\
\hline Congruent & Incongruent & With source info & $.52(2.76)$ & $.02(.36)$ \\
\hline Congruent & Balanced & & $24.19(1.94)^{* * *}$ & $1.37(.19)^{* * *}$ \\
\hline Congruent & Balanced & With source info & $.02(2.76)$ & $.48(.29) \dagger$ \\
\hline Balanced & Congruent & & $22.64(1.94)^{* * *}$ & $.91(.19)^{* * *}$ \\
\hline Balanced & Congruent & With source info & $3.88(2.76)^{\dagger}$ & $.32(.29)$ \\
\hline Balanced & Incongruent & & $4.43(1.94)^{* *}$ & $.44(.20)^{*}$ \\
\hline Balanced & Incongruent & With source info & $-1.98(2.76)$ & $.61(.30)^{*}$ \\
\hline Balanced & Balanced & & $2.39(1.94)^{* * *}$ & $.93(.19)^{* * *}$ \\
\hline Balanced & Balanced & With source info & $4.40(2.76)^{\dagger}$ & $.59(.29)^{*}$ \\
\hline Incongruent & Congruent & & $16.61(1.94)^{* * *}$ & $.90(.19)^{* * *}$ \\
\hline Incongruent & Congruent & With source info & $7.91(2.76)^{* *}$ & $.78(.29)^{* * *}$ \\
\hline Incongruent & Balanced & & $2.81(1.94)^{* * *}$ & $.23(.20)$ \\
\hline Incongruent & Balanced & With source info & $1.52(2.76)$ & $.65(.30)^{*}$ \\
\hline \multirow[t]{4}{*}{ Source } & & & $.33(2.56)$ & $.54(.23)^{*}$ \\
\hline & Constant & & $39.74(1.80)$ & $-1.31(.15)$ \\
\hline & ICC level & & .421 & $2.01 e-15$ \\
\hline & LL full model & & -22171.35 & -2882.875 \\
\hline
\end{tabular}

Notes: $\uparrow p<.10 ;{ }^{*} p<.05 ;{ }^{* *} p<.01 ;{ }^{* * *} p<.001$. Reference category is news item with incongruent headline and incongruent image. Regarding the "Interaction source information" column: coefficients adjacent to "With source info" shows the additional effect of the addition of source information beyond the effect without a source (shown by the coefficients adjacent to blank space). Cells contain unstandardized regression coefficients with standard errors. IIC = Intraclass correlation coefficient; LL = Log likelihood. 
Table B2. Refugees context, multilevel models explaining peoples' likelihood of viewing and selection of a news item, interacted with source information.

\begin{tabular}{lllcc}
\hline \multicolumn{2}{c}{ News item type } & & \multicolumn{2}{c}{ Dependent variable } \\
\hline Image & Headline & Interaction source information & Likelihood rating & Selection \\
\hline Congruent & Congruent & & $3.37(1.94)^{*}$ & $-.13(.18)$ \\
Congruent & Congruent & With source info & $.56(2.76)$ & $.20(.25)$ \\
Congruent & Incongruent & & $-17.69(1.94)^{* * *}$ & $-1.36(.21)^{* * *}$ \\
Congruent & Incongruent & With source info & $-3.88(2.76)$ & $-.57(.32)^{\dagger}$ \\
Congruent & Balanced & & $3.80(1.94)^{*}$ & $.44(.17)^{* *}$ \\
Congruent & Balanced & With source info & $-4.37(2.76)$ & $-.12(.25)$ \\
Balanced & Congruent & & $2.25(1.94)$ & $-.02(.18)$ \\
Balanced & Congruent & With source info & $-.52(2.76)$ & $-.27(.25)$ \\
Balanced & Incongruent & & $-15.96(1.94)^{* * *}$ & $-.49(.18)^{* *}$ \\
Balanced & Incongruent & With source info & $-6.38(2.76)^{*}$ & $.02(.26)$ \\
Incongruent & Incongruent & & $-2.39(1.94)^{* * *}$ & $-.93(.19)^{* * *}$ \\
Incongruent & Incongruent & With source info & $-4.40(2.76)^{\dagger}$ & $-.59(.29)^{*}$ \\
Incongruent & Congruent & & $-3.79(1.94)^{*}$ & $-.03(.18)$ \\
Incongruent & Congruent & With source info & $3.51(2.76)$ & $.18(.25)$ \\
Incongruent & Balanced & & $.41(1.94)$ & $-.70(.19)^{* * *}$ \\
Incongruent & Balanced & With source info & $-2.87(2.76)$ & $.06(.26)$ \\
\hline Source & & & $4.07(2.56)$ & $.06(.18)$ \\
& Constant & & $6.13(1.80)^{* * *}$ & $-.38(.12)^{* *}$ \\
& ICC level & & .421 & $4.86 e-13$ \\
& LL full model & & -22171.35 & -2882.86 \\
\hline
\end{tabular}

Notes: $\uparrow p<.10 ;{ }^{*} p<.05 ;{ }^{* *} p<.01 ; * * p<.001$. Reference category is news item with balanced headline and balanced image. Regarding the "Interaction source information" column: coefficients adjacent to "With source info" shows the additional effect of the addition of source information beyond the effect without a source (shown by the coefficients adjacent to blank space). Cells contain unstandardized regression coefficients with standard errors. IIC = Intraclass correlation coefficient; $\mathrm{LL}=$ Log likelihood. 
Table B3. Gun ownership context, multilevel models explaining peoples' likelihood of viewing and selection of a news items, interacted with source information.

\begin{tabular}{lllcc}
\hline \multicolumn{2}{c}{ News item type } & & \multicolumn{2}{c}{ Dependent variable } \\
\hline Image & Headline & Interaction source information & Likelihood rating & Selection \\
\hline Congruent & Congruent & & $14.45(2.02)^{* * *}$ & $.79(.20)^{* * *}$ \\
Congruent & Congruent & With source info & $8.13(2.91)^{* *}$ & $.38(.29)$ \\
Congruent & Incongruent & & $.49(2.02)$ & $.10(.22)$ \\
Congruent & Incongruent & With source info & $3.13(2.88)$ & $-.06(.32)$ \\
Congruent & Balanced & & $19.61(2.02)^{* * *}$ & $1.56(.20)^{* * *}$ \\
Congruent & Balanced & With source info & $4.78(2.87)^{\dagger}$ & $-.14(.29)$ \\
Balanced & Congruent & & $14.38(2.02)^{* * *}$ & $.76(.20)^{* * *}$ \\
Balanced & Congruent & With source info & $8.68(2.88)^{* *}$ & $.29(.29)$ \\
Balanced & Incongruent & & $-.74(2.02)$ & $.05(.22)$ \\
Balanced & Incongruent & With source info & $7.22(2.88)$ & $.00(.32)$ \\
Balanced & Balanced & & $16.03(2.02)^{* * *}$ & $1.26(.20)^{* * *}$ \\
Balanced & Balanced & With source info & $6.96(2.88)^{*}$ & $.06(.29)$ \\
Incongruent & Congruent & & $13.17(2.02)^{* * *}$ & $.86(.20)^{* * *}$ \\
Incongruent & Congruent & With source info & $9.43(2.88)^{*}$ & $.20(.29)$ \\
Incongruent & Balanced & & $17.43(2.02)^{* * *}$ & $1.25(.20)^{* * *}$ \\
Incongruent & Balanced & With source info & $6.48(2.88)^{*}$ & $.13(.29)$ \\
\hline Source & & & $4.82(2.63)^{\dagger}$ & $-.12(.23)$ \\
& Constant & & $43.97(1.84)^{* * *}$ & $-1.48(.16)^{* * *}$ \\
& ICC level & & .398 & $2.49 \mathrm{e}-28$ \\
& LL full model & & -22495.32 & -2903.98 \\
\hline
\end{tabular}

Note: $\uparrow \mathrm{p}<.10 ;{ }^{*} \mathrm{p}<.05 ;{ }^{* *} \mathrm{p}<.01 ;{ }^{* * *} \mathrm{p}<.001$. Reference category is news item with incongruent headline and incongruent image. Regarding the "Interaction source information" column: coefficients adjacent to "With source info" shows the additional effect of the addition of source information beyond the effect without a source (shown by the coefficients adjacent to blank space). Cells contain unstandardized regression coefficients with standard errors. IIC = Intraclass correlation coefficient; LL = Log likelihood. 
Table B4. Gun ownership context, multilevel models explaining peoples' likelihood of viewing and selection of a news item, interacted with source information.

\begin{tabular}{lllcc}
\hline \multicolumn{2}{c}{ News item type } & & \multicolumn{2}{c}{ Dependent variable } \\
\hline Image & Headline & Interaction source information & Likelihood rating & Selection \\
\hline Congruent & Congruent & & $-1.57(2.02)$ & $-.47(.18)^{* *}$ \\
Congruent & Congruent & With source info & $1.17(2.89)$ & $.32(.25)$ \\
Congruent & Incongruent & & $-15.54(2.02)^{* * *}$ & $-1.17(.20)^{* * *}$ \\
Congruent & Incongruent & With source info & $-3.83(2.86)$ & $-.12(.28)$ \\
Congruent & Balanced & & $3.58(2.02)^{\dagger}$ & $.30(.17)^{\dagger}$ \\
Congruent & Balanced & With source info & $-2.19(2.85)$ & $-.20(.24)$ \\
Balanced & Congruent & & $-1.64(2.02)$ & $-.50(.18)^{* *}$ \\
Balanced & Congruent & With source info & $1.72(2.86)$ & $.22(.25)$ \\
Balanced & Incongruent & & $-16.76(2.02)^{* * *}$ & $-1.21(.20)^{* * *}$ \\
Balanced & Incongruent & With source info & $.26(2.86)$ & $-.06(.28)$ \\
Incongruent & Incongruent & & $-16.03(2.02)^{* * *}$ & $-1.26(.20)^{* * *}$ \\
Incongruent & Incongruent & With source info & $-6.96(2.88)^{*}$ & $-.06(.29)$ \\
Incongruent & Congruent & & $-2.86(2.02)$ & $-.41(.18)^{* * *}$ \\
Incongruent & Congruent & With source info & $2.47(2.86)$ & $.14(.25)$ \\
Incongruent & Balanced & & $1.41(2.02)$ & $-.02(.17)$ \\
Incongruent & Balanced & With source info & $-.49(2.86)$ & $.07(.25)$ \\
\hline Source & & & $2.15(2.61)$ & $-.06(.17)$ \\
& Constant & & $6.00(1.84)^{* * *}$ & $-.22(.12)^{\dagger}$ \\
& ICC level & & .398 & $4.06 \mathrm{e}-15$ \\
& LL full model & & -22495.32 & -2903.98 \\
\hline
\end{tabular}

Notes: $\uparrow p<.10 ;{ }^{*} p<.05 ;{ }^{* *} p<.01 ; * * p<.001$. Reference category is news item with balanced headline and balanced image. Regarding the "Interaction source information" column: coefficients adjacent to "With source info" shows the additional effect of the addition of source information beyond the effect without a source (shown by the coefficients adjacent to blank space). Cells contain unstandardized regression coefficients with standard errors. IIC = Intraclass correlation coefficient; $\mathrm{LL}=$ Log likelihood. 